\title{
Testing a pyroclimatic hypothesis on the Mexico-United States border
}

\author{
Peter Z. Fulé,,${ }^{1,5}$ Larissa L. Yocom,${ }^{1}$ Citlali Cortés Montaño, ${ }^{1,2}$ Donald A. Falk, ${ }^{3}$ Julián Cerano, ${ }^{4}$ And \\ José VillanueVA-Díaz \\ ${ }^{1}$ School of Forestry, Northern Arizona University, P.O. Box 15018, Flagstaff, Arizona 86011 USA \\ ${ }^{2}$ ITESM-Monterrey, Dirección para el Legado de Sostenibilidad, Monterrey, Mexico \\ ${ }^{3}$ School of Natural Resources and the Environment, and Laboratory of Tree-Ring Research, University of Arizona, \\ Tucson, Arizona 85721 USA \\ ${ }^{4}$ Instituto Nacional de Investigaciones Forestales y Agropecuarias, Centro Nacional de Investigación Disciplinaria en Relación Agua, \\ Suelo, Planta Gómez Palacio, Durango 35140 Mexico
}

\begin{abstract}
The "pyroclimatic hypothesis" proposed by F. Biondi and colleagues provides a basis for testable expectations about climatic and other controls of fire regimes. This hypothesis asserts an a priori relationship between the occurrence of widespread fire and values of a relevant climatic index. Such a hypothesis provides the basis for predicting spatial and temporal patterns of fire occurrence based on climatic control. Forests near the MexicoUnited States border offer a place to test the relative influence of climatic and other controls in mountain ranges that are ecologically similar and subject to broadly similar top-down climatic influence, but with differing cultural influences. We tested the pyroclimatic hypothesis by comparing fire history information from the Mesa de las Guacamayas, a mountain range in northwestern Chihuahua, with previously published fire data from the Chiricahua Mountains, in southeastern Arizona, approximately $150 \mathrm{~km}$ away. We developed a priori hypothetical models of fire occurrence and compared their performance to empirical climate-based models. Fires were frequent at all Mesa de las Guacamayas study sites through the mid-20th century and continued uninterrupted to the present at one site, in contrast to nearly complete fire exclusion after 1892 at sites in the Chiricahua Mountains. The empirical regression models explained a higher proportion of the variability in fire regime associated with climate than did the a priori models. Actual climate-fire relationships diverged in each country after 1892 . The a priori models predicted continuing fires at the same rate per century as prior to 1892; fires did in fact continue in Mexico, albeit with some alteration of fire regimes, but ceased in the United States, most likely due to changes in land use. The cross-border comparison confirms that a frequent-fire regime could cease without a climatic cause, supporting previous arguments that bottom-up factors such as livestock grazing can rapidly and drastically alter surface fire regimes. Understanding the historical patterns of climate controls on fire could inform the use of historical data as ecological reference conditions and for future sustainability.
\end{abstract}

Key words: climatic control; fire regime; fire scar; land use; Pinus durangensis; Pinus ponderosa var. arizonica; Pinus strobiformis; Rhynchopsitta pachyrhyncha.

\section{INTRODUCTION}

Drought historically influenced burn synchrony in long-needled pine ecosystems of western North America at local to intercontinental scales (Swetnam and Baisan 2003, Kitzberger et al. 2007, Heyerdahl et al. 2008, Falk et al. 2011), affecting tree regeneration and forest density (Brown and $\mathrm{Wu} 2005$ ) and fuel quantity and spatial arrangement (Stephens 2004). Interruption of frequent, surface-fire regimes in the western United States due to human-caused factors of livestock grazing (Savage and Swetnam 1990, Belsky and Blumenthal 1997), logging

Manuscript received 4 November 2011; revised 8 February 2012; accepted 8 February 2012. Corresponding Editor: B. P. Wilcox

${ }^{5}$ E-mail: pete.fule@nau.edu
(Naficy et al. 2010), and fire suppression (Pyne 1982) beginning in the late 19th century overrode the connection between climate and fire (Swetnam and Baisan 2003, Heyerdahl et al. 2008). In recent decades, however, a lengthy period of fire exclusion has begun to be broken by fires of increasing size (Westerling et al. 2006) and severity (Miller et al. 2009). Westerling et al. (2006) argued that increased burning has been "driven primarily by sensitivity of fire regimes to recent changes in climate over a relatively large area" [emphasis added]. The degree to which climate forcing will control future fire regimes has strong implications for ecosystem management, since climate models predict drier future climate in the southwestern United States and northwestern Mexico (McKenzie et al. 2004, Seager et al. 2007, 2009). 
A detailed reconstruction of the fire-climate relationship is thus central to understanding factors that regulate fire regimes across scales of space and time. Biondi et al. (2011) noted that studies of fire-climate relationships using paleoarchives have been done primarily by correlating fire observations, usually from crossdated fire-scarred trees, with independent climate data (e.g., Schoennagel et al. 2007). The correlative approach has provided valuable insights about associations between climate and fire, but Biondi et al. (2011) noted that potentially spurious responses could be inferred in the absence of strong hypothesis testing with explicit, a priori assumptions against which to test empirical observations of fire occurrence. Therefore, they proposed the use of hypothetical a priori fire regimes based on previously published relationships between drought (such as the Palmer drought severity index, PDSI) and fire. The predicted fire occurrence under this "pyroclimatic hypothesis" can then be compared to empirical fire history data, and the hypothesis either rejected or found consistent with data. In their case study, Biondi et al. (2011) proposed two hypotheses that differed in the lagging effect of prioryear climate: a "dry" hypothesis predicting that fires were more likely in dry years, and a "wet" hypothesis that predicted that fires were likely in dry years that followed wet years, a pattern previously observed in the southwestern United States (Swetnam and Baisan 2003).

Biondi et al. (2011) tested the a priori models against data from an empirical fire regime reconstructed from 197 fire-scarred trees at $\mathrm{Mt}$ Irish, a mountain range in southeastern Nevada. Fires were frequent from ca. 1550, the start of adequate sample depth, until 1860, approximately the date of European settlement and removal of the Native American population (Biondi et al. 2011). The fire exclusion date was similar to those of surrounding sites in the Southwest and Sierra Nevada (Savage and Swetnam 1990, Swetnam and Baisan 2003). However, the expected fire regime based on PDSI alone also predicted a $50 \%$ or more reduction in fire after 1860 , leading them to conclude that "less favorable climatic conditions, and not post-settlement fire management, were responsible for reduced wildfire occurrence in the modern era."

The study by Biondi et al. (2011) provides a framework for testing fire-climate relationships against an a priori hypothesis. The statement of an explicit and falsifiable pyroclimatic hypothesis allows the relative contribution of climate variability to be isolated from other factors that may contribute to spatial and temporal variation in fire regimes. Given the implications for the dominant management paradigms for ecological restoration of surface-fire adapted, long-needled western pines (Stephens and Ruth 2005), it would be valuable to test pyroclimatic hypotheses at multiple locations, especially where the simultaneous and possibly overlapping influences of climate and humans could be disentangled. However, such testing is difficult because broad-scale fire exclusion blanketed almost all of the western United States beginning approximately 1850-1890 (Swetnam and Baisan 2003, Hessl et al. 2004, Heyerdahl et al. 2008).

Mexican forests present a distinct contrast to the widespread and nearly uniform fire exclusion elsewhere in the continental United States and southern Canada. The continuation of fire regimes in some forests south of the United States-Mexico border offers an opportunity to contrast the relative effects of climate and human factors on fire regimes. Forested ecosystems are similar on both sides of the international border, but human land-use histories are distinct (Leopold 1937, Rodríguez-Trejo 2008). Fire regimes in long-needled pine forests were similar prior to the extensive changes in the 19 th century leading to fire exclusion on the U.S. side (Minnich et al. 1995, Swetnam et al. 2001). Depending on the specific site, frequent fire regimes continued into the 1940s (Stephens et al. 2003), the 1970s (Swetnam et al. 2001), or to the present (Fulé et al. 2011) on the Mexican side (Rodríguez-Trejo 2008). Side-by-side cross-border comparisons in individual mountain ranges are not possible because the frontier does not cross high mountains (a side effect of the 1853 Gadsden Purchase that located the border in accessible terrain for a railroad [Sheridan 1995]), but there are nearby high mountain ranges north and south of the border. All of the major mountain ranges on the U.S. side of the Four Corners border region (Arizona and New Mexico, USA, Sonora and Chihuahua, Mexico) have had dendrochronological fire history reconstructions (Swetnam et al. 2001), but only the relatively low-elevation Sierra de los Ajos (Dieterich 1983) and Sierras San Luis, Panduro, and Bacadehuachi (J. Meunier and A. Arizpe, unpublished data) have been studied on the Mexican side.

We chose the Mesa de las Guacamayas (MDG), a high mountain range in northwestern Chihuahua, approximately $80 \mathrm{~km}$ south of the international border, to test a pyroclimatic hypothesis in comparison with previously published fire data from the Chiricahua Mountains, southeastern Arizona, approximately 55 $\mathrm{km}$ north of the border and $150 \mathrm{~km}$ from MDG (Fig. 1). We focused analysis on these two ranges because they form a comparable pair of geographically proximate high-elevation forests with similar climate regimes but differing land use histories. This research had three objectives: (1) characterize the fire regime in relict unharvested stands of a remote Mexican forest with high conservation value; (2) develop a priori expected regional fire regimes to test a null pyroclimatic hypothesis in similar forests on either side of the border; and (3) compare the performance of the a priori expected fire regime with empirical, site-specific fireclimate relationships, to assess the degree to which climate can explain variability in fire occurrence.

\section{Methods}

\section{Fire regime at Mesa de las Guacamayas, Chihuahua}

We selected four unharvested forest stands, each approximately 12 ha, at MDG in northwestern Chihua- 


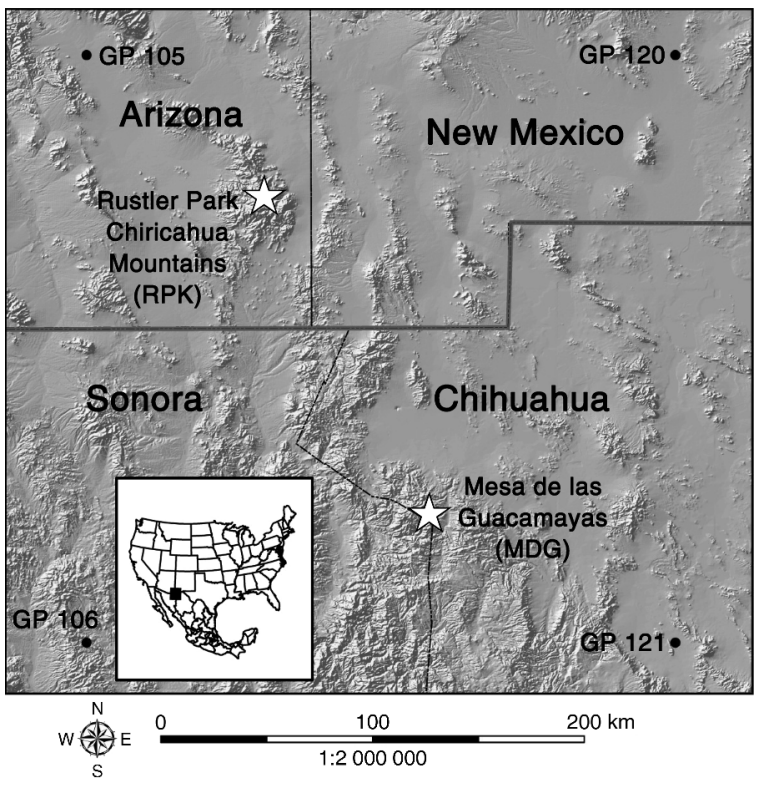

FIG. 1. Location of the Mesa de las Guacamayas (MDG) in northwestern Chihuahua, Mexico and Rustler Park (RPK) in the Chiricahua Mountains, southeastern Arizona, USA. Grid points (GP) are from the Palmer drought severity index reconstruction by Cook et al. (2004). The inset map shows the study region on the Mexico-U.S. border.

hua, Mexico (Table 1). Sites were chosen to simultaneously characterize the fire regime together with old forest composition and structure in a companion study (Cortés Montaño 2011). The lands are managed by the Ejido 5 de Mayo, a communal holding covering over 25000 ha established by presidential decree in 1972 (RAN 2010). Timber cutting was done on large concessions in the early 20th century (Palomares Peña 1991), but records are poor. C. Cortés Montaño, P. Z. Fulé, D. A. Falk, J. Villanueva-Díaz, and L. L. Yocom (unpublished manuscript) could not confirm whether the MDG study sites were included in a concession. At least one sawmill operated nearby in the 1960s until the ejido was formed in the 1970s. Under ejido management, further logging occurred up to the late 1990s (Cortés Montaño et al., unpublished manuscript). Currently only one family resides at MDG and there is light livestock grazing (Cortés Montaño et al., unpublished manuscript). Broadly speaking, fire management policies in Mexico focus on fire suppression, but in practice fires are frequent in many locations (Rodríguez-Trejo 2008). Current fire management at MDG includes a seasonally staffed lookout, and ejido members are summoned to help extinguish fires. Logging activities have reduced the area of old forest, but the mountain range retains important high-elevation forest habitat, including for the rare Thick-billed Parrot, Rhynchopsitta pachyrhyncha (Monterrubio-Rico and Enkerlin-Hoeflich 2004). Tree species include Cupressus arizonica, Pinus durangensis, P. strobiformis, Pseudotsuga menziesii, and Quercus spp. and other broadleaved species (Cortés Montaño 2011).

Each 12-ha study site was searched thoroughly for fire-scarred trees (see Plate 1). Partial cross-sections were cut from scarred "catfaces" on trees, snags, logs, and stumps of conifers apparently containing the oldest and/ or most extensive fire records, as evidenced by having numerous externally visible fire scars, large size, and evidence of old age (many tree rings) in the cases where the rings were visible, such as a broken tree. In the lab, samples were mounted and surfaced until cell structure could be seen clearly under a microscope. Samples were crossdated using characteristic patterns of narrow marker years (Stokes and Smiley 1968). A master treering chronology developed from unscarred Pseudotsuga menziesii trees in MDG was also used in crossdating (J. Villanueva-Díaz, unpublished data). After dating, ring widths of all samples were measured in order to check dating with the COFECHA program (Grissino-Mayer 2001a). The season of fire occurrence was estimated based on the relative position of each fire lesion within the annual ring according to the following categories: EE (early earlywood), ME (middle earlywood), LE (late earlywood), L (latewood), and D (dormant or ring boundary). Dormant season scars were assigned to the year of the following earlywood (i.e., spring fires) as in other studies in Chihuahua (Heyerdahl and Alvarado 2003) and Arizona (Swetnam and Baisan 2003) based on observations of fire seasonality in the region.

TABle 1. Study site and fire-scarred tree characteristics.

\begin{tabular}{|c|c|c|c|c|c|}
\hline Study site & $\begin{array}{l}\text { Site } \\
\text { code }\end{array}$ & $\begin{array}{c}\text { Average } \\
\text { elevation (m) }\end{array}$ & $\begin{array}{l}\text { Average } \\
\text { slope (\%) }\end{array}$ & $\begin{array}{l}\text { No. samples } \\
\text { collected/crossdated }\end{array}$ & $\begin{array}{l}\text { Average diameter }(\mathrm{cm}) \\
\text { of sampled trees } \\
\text { (all species) }\end{array}$ \\
\hline \multicolumn{6}{|c|}{ Mesa de las Guacamayas, Chihuahua, Mexico } \\
\hline Mesa Prieta & MP & 2375 & 60 & $51 / 47$ & 57.7 \\
\hline Prieta Sur & PS & 2409 & 46 & $31 / 29$ & 79.9 \\
\hline Rincón de las Tinajas & RT & 2467 & 59 & $48 / 47$ & 54.3 \\
\hline El Abeto & $\mathrm{AB}$ & 2476 & 63 & $37 / 34$ & 59.3 \\
\hline \multicolumn{6}{|l|}{ Rustler Park, Arizona, USA } \\
\hline Rustler Park & RPK & 2591 & NR & $63 / 63$ & NR \\
\hline
\end{tabular}

Notes: At Mesa de las Guacamayas, each site was approximately 12 ha in extent. The Rustler Park site was a transect $3.2 \mathrm{~km}$ in length, but width was not reported (Seklecki et al. 1996). NR denotes data not reported by Seklecki et al. (1996). 
Fire history data were analyzed with the FHX2 software, version 3.2 (Grissino-Mayer 2001b). Analysis at each site was started from the first year with an adequate sample depth, defined as the first fire year recorded by $10 \%$ or more of the total number of recording trees at each site. "Recording" trees are those with open fire scars or other injuries, such as lightning scars, leaving them susceptible to repeated scarring by fire. The ending date for analysis was 2008, the last completed tree ring before sampling. The period of analysis for all fire-scarred samples combined was 17332008.

We assessed the statistical distribution of fire intervals using all fire years and those fire years in which $25 \%$ or more of the recording samples were scarred. The $25 \%$ filter represents fires that were relatively widespread (Swetnam and Baisan 2003). Fire interval distributions are typically non-normal, so we fit Weibull models to the empirical fire-interval distributions and tested for adequate fit (Kolmogorov-Smirnov test, alpha $=0.05$ ).

\section{Fire regime at Chiricahua Mountains, Arizona}

Fire data for comparison to the Chihuahua sites were collected and analyzed by Seklecki et al. (1996). They sampled fire-scarred $P$. ponderosa var. arizonica and $P$. strobiformis trees along a $3.2-\mathrm{km}$ transect through Rustler Park (RPK), average elevation $2591 \mathrm{~m}$, in the Coronado National Forest. We downloaded the fire data from the International Multiproxy Paleofire Database (available online). ${ }^{6}$ We calculated statistics on the all-scarred and 25\%-scarred fire interval distributions as described above, using the common starting date of 1733. However, fires ceased at Rustler Park after 1892 except for a 1950 fire that scarred two trees; Seklecki et al. (1996) attributed the fire exclusion after 1892 to livestock grazing and fire suppression.

\section{Modeling and climate}

There are numerous climatic variables that could be candidates to develop a priori hypotheses: drought indices, annual or seasonal precipitation, temperature, El Niño/Southern Oscillation (ENSO) and other globalscale climatic oscillations, or recurring regional climate patterns such as the Mexican monsoon. We used reconstructed values of the Palmer drought severity index (PDSI), following the approach used by Biondi et al. (2011) in the only previously published study that developed a priori hypothetical fire regimes.

Reconstructed PDSI data were obtained from the North American Drought Atlas (Cook et al. 2004; atlas available online). ${ }^{7}$ The four grid points surrounding the four corners region of Arizona (grid point \#105), Sonora (106), New Mexico (120), and Chihuahua (121) (Fig. 1) were averaged together (Appendix). The Mexican grid points had data through 1990 and the U.S.

\footnotetext{
${ }^{6} \mathrm{http}: / /$ www.ncdc.noaa.gov/paleo/impd/paleofire.html

${ }^{7}$ http://www.ncdc.noaa.gov/paleo/newpdsi.html
}

grid points continued to 2003, so only the U.S. data were averaged for 1991-2003.

We used the averaged PDSI data from the grid points in Fig. 1 to apply a priori models using Biondi et al.'s (2011) approach. The "dry" hypothesis posits that widespread fire will occur in those years in which (1) current year PDSI was $<-3$, or (2) current year PDSI was $<0$ and prior year PDSI was $<-3$, or (3) current and prior year PDSI were both $<0$ and PDSI two years prior was $<-3$. The "wet" hypothesis incorporates a lagging effect of moisture in prior years, positing that fire occurred when (1) current year PDSI was $<0$ and prior year PDSI was $>2$ or (2) current year PDSI was $<0$, prior year PDSI was $>0$, and PDSI two years before was $>2$. In both regimes, no fire could occur if fire had happened the year before. The dry and wet terminology was suggested by Biondi et al. (2011). For clarity, fires are predicted to occur in dry years under both hypotheses, but they differ in whether preceding years were dry or wet. There is multicollinearity among the different lags of PDSI, but we were not testing the strength of the different parameters in the model.

In addition to these a priori models, we enhanced the Biondi et al. (2011) approach by developing separate empirical models to predict fire occurrence at MDG and RPK using logistic regression with the dependent variable of fire occurrence $(0,1)$ and the same three independent variables as the a priori models: PDSI in the current year and lagged by 1 and 2 years. The modeling period at MDG was 1733-2008; at RPK it was 1733-1892. Models were developed for the all-scar and $25 \%$-scarred data from both MDG and RPK. Logistic regression models were developed for 1-4 parameters, ranging from the constant-only model to constant + the three PDSI variables. The logistic model predicted fire probability $\pi$ at date $t$ as follows:

$$
\pi(t)=\frac{\exp \left(\alpha+\beta_{1} x_{1}+\beta_{2} x_{2}+\ldots\right)}{1+\left(\exp \left(\alpha+\beta_{2} x_{1}+\beta_{2} x_{2}+\ldots\right)\right)}
$$

where $\alpha$ and $\beta$ are regression parameters, $x$ is an independent variable, and subscripts 1 and 2 refer to years 1 and 2. We evaluated the models in each set based on Akaike's information criterion (AIC) and model weight (proportion of log-likelihood explained by the model), favoring models with low AIC and high weight. We adjusted the fire probability threshold of each model to match the empirically observed number of fires. For example, if a site had 37 fires in the period of analysis, we set the logistic model probability threshold to the level that resulted in 37 predicted fire dates for the same period of analysis. This empirical model provided an objective standard against which the a priori pyroclimatic hypotheses could be tested.

We assessed the accuracy of both a priori and empirical models by comparing the synchrony of predicted and observed fire years as well as assessing the statistics of the aggregate fire regime. Biondi et al. 
TABLE 2. Statistics of fire interval distributions.

\begin{tabular}{|c|c|c|c|c|c|c|c|}
\hline Site/analysis period & $\begin{array}{c}\text { Category of } \\
\text { analysis }\end{array}$ & $\begin{array}{c}\text { No. } \\
\text { intervals }\end{array}$ & MFI & Min & Max & $\begin{array}{l}\text { Average per-sample } \\
\text { fire interval }\end{array}$ & WMPI \\
\hline \multicolumn{8}{|c|}{ Mesa de las Guacamayas, Chihuahua, Mexico } \\
\hline \multirow[t]{2}{*}{ MP 1752-2008 } & all scars & 34 & 7.3 & 1 & 35 & \multirow[t]{4}{*}{18.2} & 6.4 \\
\hline & $25 \%$ scarred & 26 & 9.6 & 3 & 44 & & 8.3 \\
\hline \multirow[t]{2}{*}{ MP $1752-1945$} & all scars & 31 & 6.2 & 1 & 17 & & 5.9 \\
\hline & $25 \%$ scarred & 24 & 8.0 & 3 & 17 & & 7.7 \\
\hline \multirow[t]{2}{*}{ PS $1760-2008$} & all scars & 26 & 9.3 & 1 & 35 & \multirow[t]{4}{*}{23.2} & 8.0 \\
\hline & $25 \%$ scarred & 17 & 14.2 & 3 & 44 & & 13.1 \\
\hline \multirow[t]{2}{*}{ PS $1760-1945$} & all scars & 22 & 8.4 & 1 & 23 & & 7.4 \\
\hline & $25 \%$ scarred & 15 & 12.3 & 3 & 23 & & 12.2 \\
\hline \multirow[t]{2}{*}{ RT 1799-2008 } & all scars & 33 & 6.2 & 1 & 12 & \multirow[t]{2}{*}{12.2} & 6.0 \\
\hline & $25 \%$ scarred & 25 & 8.1 & 2 & 20 & & 7.8 \\
\hline \multirow[t]{2}{*}{ AB $1785-2008$} & all scars & 29 & 7.5 & 2 & 28 & \multirow[t]{6}{*}{17.0} & 6.6 \\
\hline & $25 \%$ scarred & 21 & 10.3 & 4 & 49 & & 8.7 \\
\hline AB $1785-1953$ & all scars & 26 & 6.5 & 2 & 17 & & 6.0 \\
\hline \multirow{3}{*}{ MDG all, 1733-2008 } & $25 \%$ scarred & 20 & 8.4 & 4 & 19 & & 8.1 \\
\hline & all scars & 68 & 4.0 & 1 & 11 & & 3.7 \\
\hline & $25 \%$ scarred & 37 & 7.5 & 1 & 16 & & 7.3 \\
\hline \multicolumn{8}{|l|}{ Rustler Park, Arizona, USA } \\
\hline \multirow[t]{2}{*}{ RPK 1733-1892 } & all scars & 54 & 2.9 & 1 & 16 & & 2.6 \\
\hline & $25 \%$ scarred & 30 & 5.1 & 2 & 16 & & 4.8 \\
\hline
\end{tabular}

Notes: Statistical analysis was carried out in two categories: (1) all fire years, including those represented by a single fire scar, and (2) fire years in which $25 \%$ or more of the recording sample trees were scarred. All Weibull models fit the data (KolmogorovSmirnoff test). For Mesa de las Guacamayas (MDG), analysis was carried out from the first fire date with a depth of recording samples $=10 \%$ of total sample size until the final fire date. At the three sites where unusually long fire-free intervals were encountered in the 20th century, a second analysis was done ending at the last fire before the 20th-century change in fire regime. The per-sample fire intervals were calculated for the full period of record of each sample and averaged by site. The Rustler Park analysis begins in 1733 to match MDG so the statistics differ slightly from Seklecki et al. (1996; Table 1), who began at 1700. Abbreviations are: MFI, mean fire interval; min, minimum; max, maximum; WMPI, Weibull median probability interval.

(2011) noted that a priori models were not accurate at identifying specific fire years at their Nevada study site, but stated that "one would not expect climate-driven fire occurrence to be reflected in such small-scale fires." We held the opposite expectation, believing that climatic variability should closely match fire occurrence, for two reasons: (1) the purpose of building hypothetical models scaled to interannually lagged PDSI values implies that inter-annual drought variation is linked to fire occurrence as a specific, annually resolved causal mechanism. (2) Both the southwestern United States (Swetnam and Baisan 2003) and the Sierra Madre Occidental of northern Mexico (Yocom 2011) show high regional fire synchrony, which is attributed to regional climatic variability. Thus it is logical to use the synchrony of predicted vs. observed fire dates as the standard for comparing model performance.

\section{Results}

\section{Fire regime at Mesa de las Guacamayas, Chihuahua}

We collected 167 fire-scarred samples at Mesa de las Guacamayas and successfully crossdated 157 (94\%; Table 1). The season of fire occurrence was determined for $61-74 \%$ of the samples; the most common seasonal position was middle earlywood (41-45\%), the least common was latewood ( $0-2 \%$; Appendix).

Fires were frequent at MDG over the past three centuries (Table 2): for all scars, all mean fire interval (MFI) and Weibull median probability intervals
(WMPI) were $<10 \mathrm{yr}$. For the larger fires represented by the $25 \%$-scarred distributions, MFI and WMPI values were all $<15 \mathrm{yr}$. The averages of the per-sample fire intervals were all $<25$ yr. Minimum fire-free intervals ranged from 1 to $4 \mathrm{yr}$. The earliest fire date recorded was 1733 (Fig. 2). Although the study sites were separated by several kilometers (Fig. 1), fire dates in many years were synchronous across sites (Fig. 2). Fires recurred consistently until the mid-20th century, although unusually long fire-free gaps appeared after 1945 at MP and PS, and after 1953 at AB. Site RT continued to burn at historical frequencies up to the present, and all four sites burned at least once or twice since 1989 with widespread fires in 2001 and 2002; the last fire was a single scar in 2005.

\section{Fire regime at Chiricahua Mountains, Arizona}

The original data analysis for the RPK site was reported by Seklecki et al. (1996). Sixty-three firescarred samples were collected and crossdated (Table 1). We re-calculated the RPK fire regime statistics beginning in 1733 for comparison with the MDG fire regime (Fig. 2). For the period 1733-1892, fire regime statistics for the all-scar and 25\%-scarred distributions are shown in Table 3.

Fire dates at RPK were highly synchronous with those at MDG. In the 160 years of the overlapping period 1733-1892, for all fires, 29 fire dates were shared between MDG and RPK, corresponding to $69.0 \%$ of the 42 fire years in this period at MDG and $52.7 \%$ of the 55 


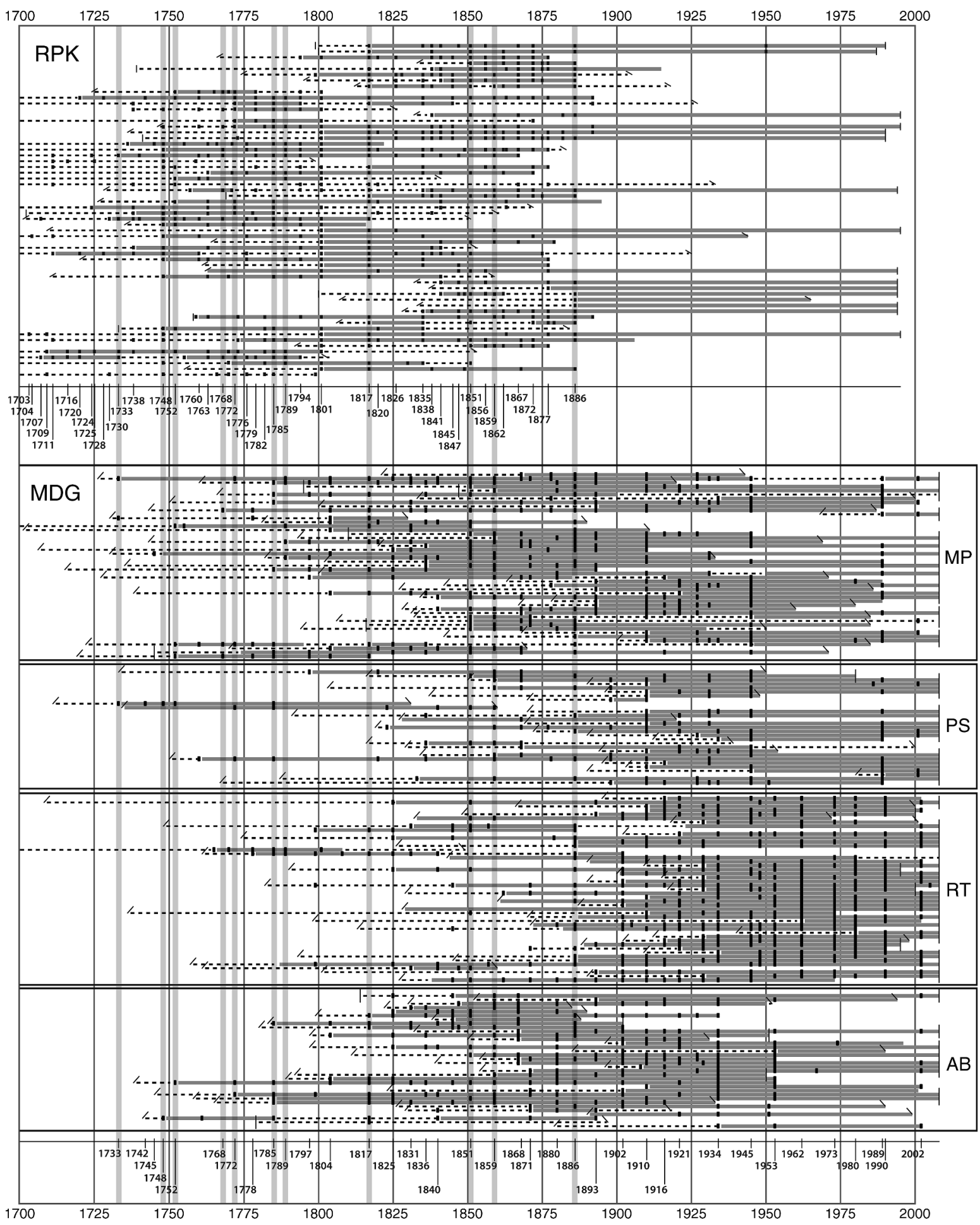

FIG. 2. (Top) Fire chart from Rustler Park (RPK), Chiricahua Mountains, Arizona (USA), redrawn from Seklecki et al. (1996). (Bottom) Mesa de las Guacamayas (MDG), Chihuahua. Horizontal lines represent trees, and thick dark vertical bars represent fire scars. Horizontal tree time lines are dashed before the first scar and solid in the recording period after being scarred. At the left of the tree time lines, a short vertical bar means that the data begin at the pith (center) of the tree; a slash means that the data begin at a tree ring, not at the pith. The composite fire history, filtered to fires that scarred at least $25 \%$ of recording trees, is shown with dates below the chart. Vertical bars at the beginning or end of each tree's time series represent the pith or bark, respectively. The thick shaded vertical bars identify fire years that were common to both RPK and MDG. 
fire years in this period at RPK. The observed synchrony of 29 dates was over twice as high as the 14.4 shared dates that would be expected based on independent probabilities of fire occurrence at each site. Making the same comparison with the $25 \%$-scarred fire dates, 11 fire dates were shared between MDG and RPK, corresponding to $47.8 \%$ of the 23 widespread fire years at MDG and $35.5 \%$ of the 31 widespread fire years at RPK. The observed synchrony of 11 dates was nearly three times higher than the four shared dates that would be expected based on the independent probabilities of fire occurrence at each site.

\section{Performance of a priori models}

The dry and wet a priori models both predicted fewer fire events than actually occurred, even after filtering the data to fires represented by $25 \%$ or more of the scars (Table 3). For example, under the category MDG all fire dates in Table 3, there were 68 actual fire dates but the dry model predicted 24 dates, of which 9 were actual fire dates; the wet model predicted 19 dates, of which 12 were actual fire dates. The percent accuracy in this category for the dry model was $38 \%$ when calculated as the ratio of correctly predicted fire dates/total predicted fire dates $(9 / 24=0.38)$, but dropped to $13 \%$ when calculated as the ratio of correctly predicted fire dates/ total observed fire dates $(9 / 68=0.13$; Table 3$)$. There are eight possible comparisons in Table 3: two models (dry and wet) $\times$ two sites $($ MDG and RPK) $\times$ two fire filters (all fires and widespread fires). Fire dates predicted by the models were highly synchronous with actual fire dates, with percent synchrony ranging from $25-63 \%$ (Table 3). The wet model consistently performed 21$25 \%$ better than the dry model. Errors of commission (prediction of a fire when one did not actually occur, calculated by subtracting the rate of accuracy from $100 \%$ ) were $\leq 50 \%$ in five of the eight instances of model-site-filter comparisons. However, errors of omission (failure to predict a fire when one did actually occur) were always $\geq 65 \%$ and ranged as high as $87 \%$ (Table 3). Neither the dry nor wet model predicted any change in fire regime before or after 1892. From 17331892, the dry model predicted 14 fires (8.8 fires/century) and the wet model predicted 11 fires (6.9 fires/century). From 1893-2003, the dry model predicted 10 fires $(9.0$ fires/century) and the wet model predicted 8 fires (7.2 fires/century).

\section{Performance of empirical models}

The best-performing empirical models of the four potential alternatives (model forms were constant $+1-3$ PDSI variables), evaluated for both study sites and both categories (all fire dates and 25\%-scarred fire dates), included three parameters: the constant, PDSI in the current year, and PDSI lagged by one year (Appendix). The best models had the lowest AIC value and highest model weights (range $0.60-0.74$ ) in every case except the RPK model for all fire dates. In this case, the three- and
TABle 3. Performance of a priori hypothetical models based on "dry" and "wet" hypotheses, compared to actual fires at Mesa de las Guacamayas (MDG) and Rustler Park (RPK).

\begin{tabular}{lcrr}
\hline \hline \multicolumn{1}{c}{ Parameter } & Actual fires & Dry model & Wet model \\
\hline MDG, all fire dates & & & \\
Time (yr) & 271 & 271 & 271 \\
No. fires & 68 & 24 & 19 \\
Years with fire (\%) & 25 & 9 & 7 \\
No. accurate & NA & 9 & 12 \\
Accuracy (\%) & $13-18 \dagger$ & 38 & 63 \\
MDG, widespread fires & & & \\
Time (yr) & 271 & 271 & 271 \\
No. fires & 37 & 24 & 19 \\
Years with fire (\%) & 14 & 9 & 7 \\
No. accurate & NA & 6 & 10 \\
Accuracy (\%) & $16-27 \dagger$ & 25 & 53 \\
RPK, all fire dates & & & \\
Time (yr) & 160 & 160 & 160 \\
No. fires & 55 & 14 & 11 \\
Years with fire (\%) & 34 & 9 & 7 \\
No. accurate & NA & 7 & 6 \\
Accuracy (\%) & $11-13 \dagger$ & 50 & 55 \\
RPK, widespread fires & & & \\
Time (yr) & 160 & 160 & 160 \\
No. fires & 31 & 14 & 11 \\
Years with fire (\%) & 11 & 9 & 7 \\
No. accurate & NA & 4 & 6 \\
Accuracy (\%) & $13-19 \dagger$ & 29 & 55 \\
\hline
\end{tabular}

Notes: Widespread fires are those fire years in which $25 \%$ or more of the samples were scarred. The number and percentage accuracy refer to the agreement between the model-predicted fires and the actual observed fires within each study area and fire filter (all fire dates/widespread fires). NA stands for not applicable.

$\dagger$ The range of accuracy between actual fire dates and modelpredicted fire dates for the model scenarios in this table.

four-parameter models were nearly identical in performance, with weights of 0.47 and 0.52 , respectively. Because the performance of the two models was nearly indistinguishable, we selected the three-parameter model for consistency with the three other best models.

Accuracy (agreement between predicted and observed fire events) of the empirical models ranged from $44 \%$ to $50 \%$ (Table 4). There are four possible comparisons in Table 4: two sites (MDG and RPK) $\times$ two fire filters (all fires and widespread fires). Errors of commission were $50-56 \%$, with only one of four filter-site comparison values $\geq 50 \%$ ) were higher than for the hypothetical models, but errors of omission were much lower (also $50-56 \%$ ), with none of the values $\geq 65 \%$, as opposed to the hypothetical models in which all eight model-filtersite comparison values were $\geq 65 \%$.

\section{Discussion}

\section{Comparison of fire regimes}

The frequent fire regimes at MDG and RPK were similar to those found elsewhere in the region. The range of MFI values for all fires, 2.9-8.4 yr, were close to the means of 5.3 and $6.8 \mathrm{yr}$ for all fires in 10 pine/mixed conifer sites and 7 mixed conifer sites, respectively, in a 
TABLE 4. Performance of empirical logistic regression models based on current-year and 1- and 2-year lagged PDSI values, compared to actual fires (all fires and 25\%-scarred fires) at Mesa de las Guacamayas (MDG) and Rustler Park (RPK).

\begin{tabular}{lrcc}
\hline \hline & \multicolumn{3}{c}{ Empirical model } \\
\cline { 2 - 4 } \multicolumn{1}{c}{ Parameter } & Actual Fires & All Fires & $\begin{array}{c}25 \% \text {-scarred } \\
\text { Fires }\end{array}$ \\
\hline MDG & & & \\
Time (yr) & 271 & 271 & 271 \\
No. fires & 68 & 68 & 37 \\
Years with fire (\%) & 25 & 25 & 14 \\
No. accurate & NA & 34 & 17 \\
Accuracy (\%) & NA & 50.0 & 46.0 \\
RPK & & & \\
Time (yr) & 160 & 160 & 160 \\
No. fires & 55 & 55 & 31 \\
Years with fire (\%) & 34 & 20 & 19 \\
No. accurate & NA & 24 & 15 \\
Accuracy (\%) & NA & 43.6 & 48.4 \\
Time (yr) & & & \\
\end{tabular}

Notes: The number and percentage accuracy refer to the agreement between the model-predicted fires and the actual observed fires. NA stands for not applicable.

comparison of all study sites in the Four Corners border region (Swetnam et al. 2001). Seasonal distribution of fire scars was also similar between MDG and RPK. The striking contrast between the Rustler Park vs. the Mesa de las Guacamayas sites is thus not in the statistical properties of the fire regimes but in their persistence over time: complete cessation of fire occurred at Rustler Park after 1892 (except for the two samples scarred in 1950). More broadly, fire exclusion occurred uniformly on the U.S. side, beginning as early as 1871 and encompassing the entire region by 1904 except for one site with a large 1953 fire (Swetnam et al. 2001). In contrast, the Mesa de las Guacamayas sites and the few other published Mexican sites in the border region did not show fire regime changes in the late 1800 s, and they varied widely in the 1900s, including some sites with no change. The latest fires at the nearest published Mexican site to MDG, the pine-oak forest in Sierra de los Ajos in Sonora (three study sites) were in 1916, 1954, and 1972 (Swetnam et al. 2001). The next closest sites are Salsipuedes in 1949 (Heyerdahl and Alvarado 2003), Tutuaca in 1955 (two sites) and uninterrupted (one site) (Fulé et al. 2005), Pino Gordo, with altered synchrony but uninterrupted (Fulé et al. 2011), and Cerro Mohinora (two sites) with continuing fires but evidence of change in synchrony and fire-free interval length in the 1950s and 1970s (Cerano Paredes et al. 2010). The only other study near the border, at Sierra San Pedro Mártir in Baja California, had a final widespread fire in 1946 but scattered smaller fires thereafter (Stephens et al. 2003).

The pattern of recent fire regime change at MDG, with two sites interrupted after 1945, one after 1953 (all three with subsequent large fires in the 1990s-2000s), and one uninterrupted site, has several implications.
First, factors affecting fire occurrence changed in the mountain range circa 1945, disrupting the previous pattern of frequent, highly synchronized fires among the four sites. Second, the change was not universal, since site RT continued to burn. Third, the similarity between the Mesa de las Guacamayas fire regime and the pre1890s fire regimes in the southwestern United States, including Rustler Park, and their strong divergence after 1890 support the proposition of using a cross-border comparison to test a pyroclimatic hypothesis.

\section{Testing the pyroclimatic hypothesis with a priori models}

A priori expectations from hypothetical models based on fire-climate relationships in the Mexico-United States borderlands were both rejected and supported, depending on time and place. The rejection of the hypothetical model is shown clearly in the sharp contrast across the border: the pyroclimatic hypothesis predicted no change in fire regime after 1892, but the previously similar fire regimes in sites on either side of the border diverged completely with fires ceasing at Rustler Park but continuing much longer in Mesa de las Guacamayas, demonstrating that this change in fire regime was not the result of climate forcing. However, the pyroclimate relationship was supported prior to 1892 at Rustler Park, and up to the present at Mesa de las Guacamayas, by the fact that predicted fire dates were highly synchronous with actual fires, although there were numerous errors of omission. There might be various reasons for the fact that fewer fire dates were predicted than observed, but a logical initial explanation is that the model used criteria at relatively high levels of PDSI, requiring several PDSI variables to be below -3 or above 2. Adjustment of these levels, in a manner analogous to the way we required the empirical model to match the observed number of fire dates, would have resulted in more predicted fire dates.

In sum, the historical fire regime on two comparable mountain ranges in the Mexico-United States borderlands was linked to climate as suggested by a priori models, similar to the observation by Biondi et al. (2011) in Nevada. But the climate-fire relationship broke down after 1892, and a climate hypothesis cannot explain the divergence in fire regimes after this period: climate-based models predicted continuing fires at the same rate per century as prior to 1892 , and fires did in fact continue in Mexico, but ceased in the United States. There are many plausible reasons for fire exclusion in the Chiricahua Mountains and the southwestern United States, especially livestock grazing and organized fire suppression (Savage and Swetnam 1990, Seklecki et al. 1996, Swetnam et al. 2001). These local, bottom-up factors, particularly land use, may affect one area but not another (Falk et al. 2011). We conclude that there is no evidence for a climatic explanation of the change in fire regime in the late 1800s at Rustler Park. This conclusion cannot be extrapolated to other locations, but the Mexico-United States comparison does show that it is 


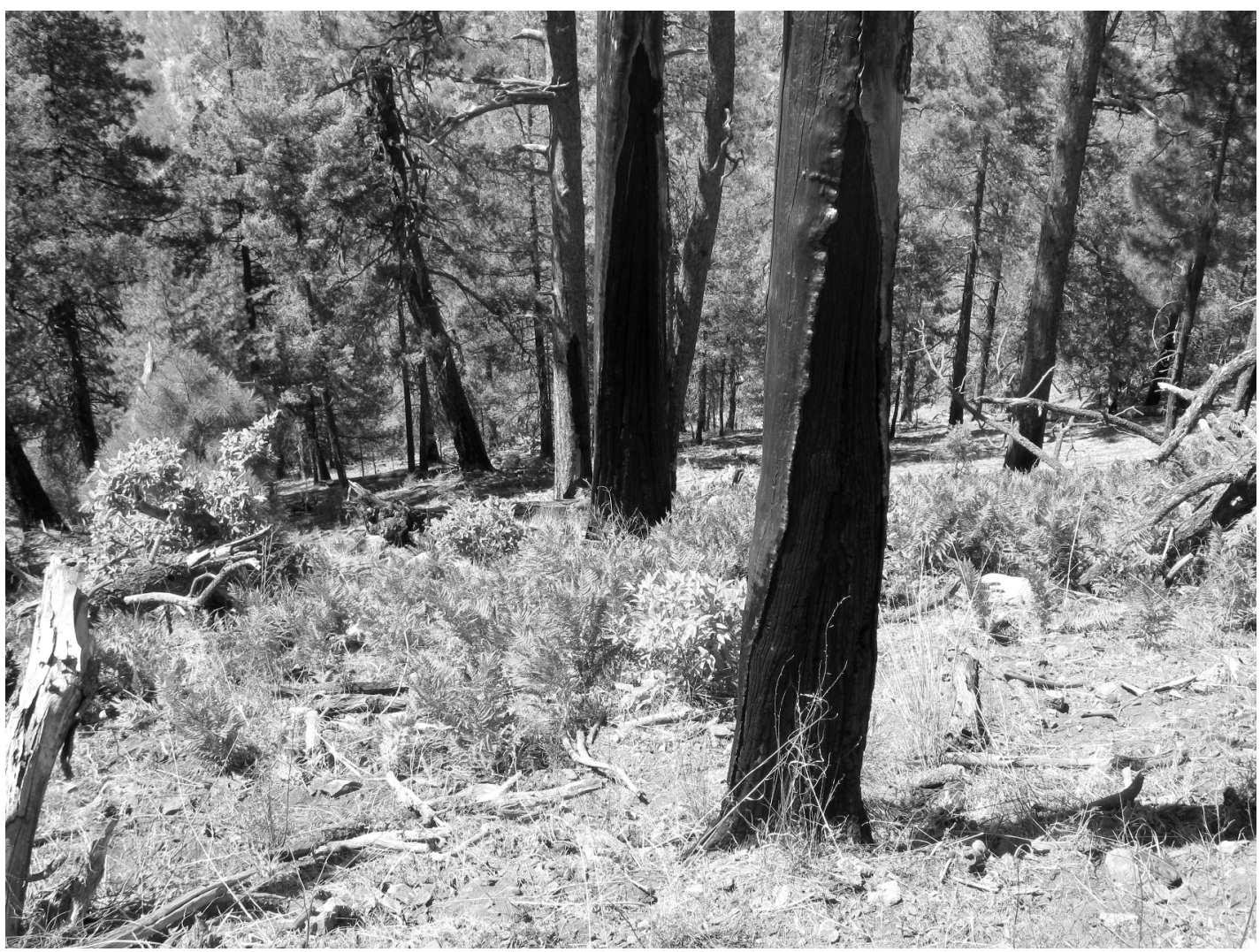

Plate 1. Fire-scarred snags and trees, shown here at the Mesa Prieta study site (Chihuahua, Mexico), were sampled to reconstruct past forest fire regimes. Photo credit: P. Z. Fulé.

possible for a frequent-fire regime to cease without a drought-related climatic mechanism.

\section{Can more variability be explained with empirical models?}

The empirical models tested were less conservative (more errors of commission) than the hypothetical models, causing agreement of predicted and actual fire years to plateau around 50\%. Because we set the logistic models to match the actual number of observed fire events, errors of omission were equal to errors of commission. If the hypothetical models were used to predict the series of historical fire events at our study sites, the predictions would be correct $13-27 \%$ of the time (a range that covers both the all-fire and 25\%scarred distributions). The empirical models, in contrast, would be correct $44-50 \%$ of the time. Thus empirical models explained an additional $17-37 \%$ of the variability in fire regime associated with variability in climate. This outcome is logical because in essence we compared a relatively simple pyroclimatic model to a flexible empirical model with more degrees of freedom. In a practical application, such as predicting future fire regimes based on forecast 21 st-century drought values (e.g., Seager et al. 2007), models based on more detailed, site-specific information could be considered more reliable. Additional research to incorporate the influence of bottom-up management actions on fire regime, such as lighting or suppressing fires, altering fuels, etc., could be a useful complement to climate-fire modeling.

The pyroclimatic hypothetical proposed by Biondi et al. (2011) and empirical models tested here were based on the same predictor variables: PDSI in the current year and lagged by 1 and 2 years. This modeling framework provided an interesting example to test a common pyroclimatic hypothesis (Biondi et al. 2011) and the potential additional explanatory power of sitespecific empirical models. But PDSI variables are not the only possible climatic predictors. A more thorough modeling approach could also consider temperature, precipitation, and climatic oscillations such as El Niño/ Southern Oscillation (ENSO), Pacific Decadal Oscillation (PDO), and the Atlantic Multi-Decadal Oscillation (AMO) (Kitzberger et al. 2007, Skinner et al. 2008). Many of these variables are likely to be intercorrelated, but with appropriate modeling techniques a concise set of predictor variables could be developed. Hypothetical models could be used to frame more complex a priori hypotheses and test purported mechanisms of climate control (e.g., multiplicative effects of ENSO and PDO). Similarly, multivariate empirical models could be developed to determine the maximum possible sitespecific variability in fire regime that can be explained by 
climate. Designing and testing a comprehensive set of a priori hypotheses should be done in the context of multiple study sites across a broad regional network (Falk et al. 2011). Pyroclimatic hypotheses also have value when they are rejected, as at RPK after 1892, because they can indicate the point of departure from dominant, top-down climate control and the shift of dominance to other factors.

\section{Conclusions}

Application of a priori climate-based models to fire regimes on either side of the Mexico-United States border was a useful technique to test the pyroclimate hypothesis. Both hypothetical and empirical models based on drought showed strong associations with fire occurrence in the Chihuahua and Arizona sites through the 19th century. However, the contrast between the predicted 20th-century fire regime vs. the observed fire regimes showed that factors other than climate were the most important controls on the post-1892 fire regime at RPK. These results support previous arguments that bottom-up factors such as livestock grazing can rapidly and drastically alter surface fire regimes. Differentiation of fire regimes among the Mesa de las Guacamayas study sites after 1945 indicates that bottom-up factors can effect change at fine spatial scales, producing different fire regimes within the same mountain range.

One application of fire regime data is to understand reference conditions of ecological pattern and process that regulated ecosystems prior to recent alterations by industrial society. It has been suggested previously that Mexican forests with continuing fire regimes could serve as points of reference for western long-needled pine forests (Leopold 1937, Marshall 1962), potentially guiding ecological restoration of altered sites (Stephens and Fulé 2005). While restoration based on historical conditions is particularly complex under changing climate (Jackson and Hobbs 2009), attributes such as fire frequency, type (surface/crown), and spatial extent in contemporary forests that match historical characteristics have long been considered measures of healthy or natural conditions (Stephenson 1999). The present analysis adds a new dimension to these reference conditions, viz. maintenance of the historical process of climate controls on fire. The fire regimes at Mesa de las Guacamayas retained their climate-fire link through the mid-20th century and up to the present at the RT site. It is reasonable to speculate that a natural climatefire link could ease the transition to future climatic regimes (Seager et al. 2009) by allowing vegetation and fuels to adapt gradually to novel climate regimes, in contrast to severe modern fires observed in fire-excluded forests of the southwestern United States (Savage and Mast 2005).

\section{ACKNOWLEDGMENTS}

Thanks to Don Teodoro Campos, Don Tomás, Nélida Barajas Acosta, and José Luis García Loya for research permission. Isaac Bickford, Edgar Bustillos Daniel, Walker
Chancellor, Marco Córdoba Castillo, Nancy Duarte, Christen Irby, Marissa Joe, Fernando Morales, and Margarita Moreno Hinojos helped with field work. Katie Ireland, Daniel Laughlin, and Elizabeth Kalies helped with statistical analysis. Amanda Stan provided helpful comments. Funding was provided through NSF grant DEB-0640351 and the Ecological Restoration Institute at Northern Arizona University.

\section{Literature Cited}

Belsky, A. J., and D. M. Blumenthal. 1997. Effects of livestock grazing on stand dynamics and soils in upland forests of the interior West. Conservation Biology 11:315-327.

Biondi, F., L. P. Jamieson, S. Strachan, and J. Sibold. 2011. Dendroecological testing of the pyroclimatic hypothesis in the central Great Basin, Nevada, USA. Ecosphere 2(1): article 5 .

Brown, P. M., and R. Wu. 2005. Climate and disturbance forcing of episodic tree recruitment in a southwestern ponderosa pine landscape. Ecology 86:3030-3038.

Cerano Paredes, J., J. Villanueva Díaz, and P. Z. Fulé. 2010. Reconstrucción de incendios y su relación con el clima para la Reserva "Cerro El Mohinora, Chihuahua." Revista Mexicana de Ciencias Forestales 1:63-74.

Cook, E. R., C. A. Woodhouse, C. M. Eakin, D. M. Meko, and D. W. Stahle. 2004. Long-term aridity changes in the western United States. Science 306:1015-1018.

Cortés Montaño, C. 2011. The treasure of the Sierra Madre: ecology of old-growth forests in Chihuahua, México. Dissertation. Northern Arizona University, Flagstaff, Arizona, USA.

Dieterich, J. H. 1983. Historia de los incendios forestales en la Sierra de los Ajos, Sonora. Nota Técnica No. 6PR-04. Centro de Investigaciones Forestales del Norte, México, D.F., México.

Falk, D. A., E. K. Heyerdahl, P. M. Brown, C. Farris, P. Z. Fulé, D. McKenzie, T. W. Swetnam, A. H. Taylor, and M. L. Van Horne. 2011. Multiscale controls of historical forest fire regimes: New insights from fire-scar networks. Frontiers in Ecology and the Environment 9:446-454.

Fulé, P. Z., M. Ramos-Gómez, C. Cortés-Montaño, and A. M. Miller. 2011. Fire regime in a Mexican forest under indigenous resource management. Ecological Applications 21:764-775.

Fulé, P. Z., J. Villanueva-Díaz, and M. Ramos-Gómez. 2005. Fire regime in a conservation reserve, Chihuahua, México. Canadian Journal of Forest Research 35:320-330.

Grissino-Mayer, H. D. $2001 a$. Evaluating crossdating accuracy: a manual and tutorial for the computer program COFECHA. Tree-Ring Research 57:205-221.

Grissino-Mayer, H. D. 2001b. FHX2-Software for analyzing temporal and spatial patterns in fire regimes from tree rings. Tree-Ring Research 57:113-122.

Hessl, A. E., D. McKenzie, and R. Schellhaas. 2004. Drought and Pacific Decadal Oscillation linked to fire occurrence in the Inland Pacific Northwest. Ecological Applications 14:425-442.

Heyerdahl, E. K., and E. Alvarado. 2003. Influence of climate and land use on historical surface fires in pine-oak forests, Sierra Madre Occidental, Mexico. Pages 196-217 in T. T. Veblen, W. L. Baker, G. Montenegro, and T. W. Swetnam, editors. Fire and climatic change in temperate ecosystems of the Western Americas. Springer-Verlag, New York, New York, USA.

Heyerdahl, E. K., P. Morgan, and J. P. Riser II. 2008. Multiseason climate synchronized historical fires in dry forests (1650-1900), Northern Rockies, USA. Ecology 89:705-716.

Jackson, S. T., and R. J. Hobbs. 2009. Ecological restoration in the light of ecological history. Science 325:567-569.

Kitzberger, T., P. M. Brown, E. K. Heyerdahl, T. W. Swetnam, and T. T. Veblen. 2007. Contingent Pacific-Atlantic Ocean influence on multicentury wildfire synchrony over western 
North America. Proceedings of the National Academy of Sciences USA 104:543-548.

Leopold, A. 1937. Conservationist in Mexico. American Forests 37:118-120, 146.

Marshall, J. T., Jr. 1962. Land use and native birds of Arizona. Journal of the Arizona Academy of Science 2:75-77.

McKenzie, D., Z. Gedalof, D. L. Peterson, and P. Mote. 2004. Climatic change, wildfire, and conservation. Conservation Biology 18:890-902.

Miller, J. D., H. D. Safford, M. Crimmins, and A. E. Thode. 2009. Quantitative evidence for increasing forest fire severity in the Sierra Nevada and Southern Cascade Mountains, California and Nevada, USA. Ecosystems 12:16-32.

Minnich, R. A., M. G. Barbour, J. H. Burk, and R. F. Fernau. 1995. Sixty years of change in Californian conifer forests of the San Bernadino Mountains. Conservation Biology 9:902914.

Monterrubio-Rico, T., and E. Enkerlin-Hoeflich. 2004. Present use and characteristics of Thick-Billed Parrot nest sites in northwestern México. Journal of Field Ornithology 75:96103.

Naficy, C., A. Sala, E. G. Keeling, J. Graham, and T. H. DeLuca. 2010. Interactive effects of historical logging and fire exclusion on ponderosa pine forest structure in the northern Rockies. Ecological Applications 20:1851-1864.

Palomares Peña, N. G. 1991. Propietarios Norteamericanos y Reforma Agraria en Chihuahua, 1917-1942. Universidad Autónoma de Ciudad Juárez, Ciudad Juárez, Chihuahua, México.

Pyne, S. J. 1982. Fire in America: a cultural history of wildland and rural fire. Princeton University Press, Princeton, New Jersey, USA.

RAN. 2010. Padrón histórico de núcleos agrarios. Registro Agrario Nacional, México, D.F., México.

Rodríguez-Trejo, D. A. 2008. Fire regimes, fire ecology, and fire management in Mexico. Ambio 37:548-556.

Savage, M., and J. N. Mast. 2005. How resilient are southwestern ponderosa pine forests after crown fires? Canadian Journal of Forest Research 35:967-977.

Savage, M., and T. W. Swetnam. 1990. Early 19th century fire decline following sheep pasturing in a Navajo ponderosa pine forest. Ecology 71:2374-2378.

Schoennagel, T., T. T. Veblen, D. Kulakowski, and A. Holz. 2007. Multidecadal climate variability and climate interactions affect subalpine fire occurrence, western Colorado (USA). Ecology 88:2891-2902.

Seager, R., M. Ting, M. Davis, M. Cane, N. Naik, J. Nakamura, C. Li, E. Cook, and D. W. Stahle. 2009. Mexican drought: an observational modeling and tree ring study of variability and climate change. Atmósfera 22:1-31.

Seager, R., et al. 2007. Model projections of an imminent transition to a more arid climate in southwestern North America. Science 316:1181-1184.
Seklecki, M. T., H. D. Grissino-Mayer, and T. W. Swetnam. 1996. Fire history and the possible role of Apache-set fires in the Chiricahua Mountains of southeastern Arizona. Pages 238-246 in P. F. Ffolliott, L. F. DeBano, M. B. Baker, G. J. Gottfried, G. Solis-Garza, C. B. Edminster, D. G. Neary, L. S. Allen, and R. H. Hamre, editors. Effects of fire on Madrean Province Ecosystems. General Technical Report RM-GTR-289. Rocky Mountain Forest and Range Experiment Station, Fort Collins, Colorado, USA.

Sheridan, T. E. 1995. Arizona: a history. The University of Arizona Press, Tucson, Arizona, USA.

Skinner, C. N., J. H. Burk, M. Barbour, E. Franco-Vizcaino, and S. L. Stephens. 2008. Long-term influences of climate on fire regimes in montane forests of northwestern Mexico. Journal of Biogeography 35:1436-1451.

Stephens, S. L. 2004. Fuel loads, snag abundance, and snag recruitment in an unmanaged Jeffrey pine-mixed conifer forest in Northwestern Mexico. Forest Ecology and Management 199:103-113.

Stephens, S. L., and P. Z. Fulé. 2005. Western pine forests with continuing frequent fire regimes: possible reference sites for management. Journal of Forestry 103(7):357-362.

Stephens, S. L., and L. W. Ruth. 2005. Federal forest-fire policy in the United States. Ecological Applications 15:532-542.

Stephens, S. L., C. N. Skinner, and S. J. Gill. 2003. Dendrochronology-based fire history of Jeffrey pine - mixed conifer forests in the Sierra San Pedro Martir, Mexico. Can. J. For. Res. 33:1090-1101

Stephenson, N. L. 1999. Reference conditions for giant sequoia forest restoration: structure, process, and precision. Ecological Applications 9:1253-1265.

Stokes, M. A., and T. L. Smiley. 1968. An introduction to treering dating. University of Chicago Press, Chicago, Illinois, USA

Swetnam, T. W., and C. H. Baisan. 2003. Tree-ring reconstructions of fire and climate history in the Sierra Nevada and southwestern United States. Pages 158-195 in Fire and climatic change in temperate ecosystems of the western Americas. T. T. Veblen, W. L. Baker, G. Montenegro, and T. W. Swetnam, editors. Springer-Verlag, New York, New York, USA.

Swetnam, T. W., C. H. Baisan, and J. M. Kaib. 2001. Forest fire histories of the sky islands of La Frontera. Pages 95-119 in G. L. Webster and. C. J. Bahre, editors. Changing plant life of La Frontera: observations on vegetation in the United States/Mexico Borderlands. University of New Mexico Press, Albuquerque, New Mexico, USA.

Westerling, A. L., H. G. Hidalgo, D. R. Cayan, and T. W. Swetnam. 2006. Warming and earlier spring increase western U.S. forest wildfire activity. Science 313:940-943.

Yocom, L. L. 2011. Influence of climate and local factors on fire in high-elevation forests of Mexico. Dissertation. Northern Arizona University, Flagstaff, Arizona, USA

\section{Supplemental Material}

Appendix
Additional fire, model, and climate data (Ecological Archives E093-162-A1).

